\title{
Comparison between Two Methods for Diagnosis of Trichinellosis: Trichinoscopy and Artificial Digestion
}

\author{
María Laura Vignau/ ${ }^{+}$, Mónica del Valle Guardis, Miguel Atilio Risso*, \\ Diego Fernando Eiras
}

\begin{abstract}
Cátedra de Parasitología y Enfermedades Parasitarias *Cátedra de Patología de Aves y Pilíferos, Facultad de Ciencias Veterinarias, Universidad Nacional de La Plata, Calle 60 y 118, La Plata (1900), Buenos Aires,

Argentina
\end{abstract}

Two direct methods for the diagnosis of trichinellosis were compared: trichinoscopy and artificial digestion. Muscles from 17 wistar rats, orally infected with 500 Trichinella spiralis encysted larvae were examined. From each of the following muscles: diaphragm, tongue, masseters, intercostals, triceps brachialis and cuadriceps femoralis, 648,440 larvae from $1 \mathrm{~g}$ samples were recovered. The linear correlation between trichinoscopy and artificial digestion was very high and significant $(r=0.94, p<0.0001)$, showing that both methods for the detection of muscular larvae did not differ significantly. In both methods, significant differences were found in the distribution of larvae per gramme of muscle.

Key words: trichinellosis - diagnosis - trichinoscopy - artificial digestion

Trichinellosis is a parasitic zoonosis which causes human infection in Argentina. During the last five years, an important increase of clinical cases has been detected (Larrieu 1981, Nader et al. 1986, Brusolini \& Gore 1992). Most of the cases were associated with the consumption of pork meat subproducts.

In Argentina two methods of diagnosis are used: trichinoscopy and artificial digestion; both methods allowing a direct observation of the larvae encysted in the skeletal muscles. Trichinoscopy is the primary method, even though, it is considered less sensitive than artificial digestion. Fifteen or more larvae per gramme of muscle, are considered necessary for detection using trichinoscopy, whereas, artificial digestion only requires four larvae per gramme (Ruitenberg \& Kampelmacher 1970, Van Knappen et al. 1980, Köhler \& Pfeiffer 1983, Acha \& Szyfres 1989). In this study, we compare the trichinoscopy method to artificial digestion in order to establish if there are significant differences in sensibility of one method with respect to the other; we also analize the distribution of larvae in the chosen muscles.

\section{MATERIALS AND METHODS}

Five months old wistar rats SPF $(n=17)$ were infected per os with 500 Trichinella spiralis encysted larvae from a strain maintained in rats since

\footnotetext{
${ }^{+}$Corresponding author. Fax: +54-21-253276

Received 2 January 1997

Accepted 16 May 1997
}

1960. Forty days after infection, the rats were euthanized using sulphuric ether vapours.

Trichinoscopy - From each animal, a $1 \mathrm{~g}$ sample was taken from the following muscles: diaphragm, tongue, masseters, intercostals, a triceps brachialis and a cuadriceps femoralis (opposite members of triceps). Samples were reduced to subsamples of 5 $\mathrm{mm}$ x $1 \mathrm{~mm}$ thickness; they were pressed between two sheets of glass and observed microscopically with 4x. Afterwards, encysted larvae were totaled. All the samples were recovered for processing by artificial digestion.

Artificial digestion - It was performed at $39^{\circ} \mathrm{C}$ for $3 \mathrm{hr}$ in a solution of $1 \%$ pepsin $(0.7$ Fip $\mu / \mathrm{mg}$ ) and $1 \% \mathrm{HCl}(37 \%)$ in distilled water, in a proportion of $15 \mathrm{ml} / \mathrm{g}$ of sample. The mixture was shaken. The larvae, were then filtered and those concentrated by sedimentation were washed and counted. The double-blind system was used in order to register the data obtained from both methods.

Statistical analysis - Analysis of variance was used: a Fisher test was applied in order to compare quantitative data; and a Chi square test for the qualitative results (Lison 1976). The obtained data were transformed for the analysis of variance and linear correlation, with the following relationships: number of larvae (x) equals the square root of (x), divided by the sample weight (Sokal \& Rohlf 1984, Kirby 1993).

\section{RESULTS}

Table I shows that the averages of larvae per gramme of $T$. spiralis detected by trichinoscopy (t) are significantly smaller in intercostals, triceps 
brachialis and cuadriceps femoralis (group a) than masseters and tongue (group b) and in these, the averages are signicantly smaller than in the diaphragm (group c), $(\mathrm{p}<0.0001)$.

In Table II, averages of larvae per gramme detected by artificial digestion are registered. Group $\mathbf{a}$ is significantly smaller than $\mathbf{b}$, and $\mathbf{b}$ is significantly smaller than $\mathbf{c}(\mathrm{p}<0.0001)$.

In Table III, averages of larvae per gramme detected by both methods are compared. Homo- geneous groups a, b, and $\mathbf{c}$ are identified. Those differing significantly from each while other, demonstrating the same tendency observed, using each method $(\mathrm{p}<0.0001)$.

Analysis of both methods shows similar results; both averages do not show significant differences. Through the linear correlation analysis, a significant and high coefficient was obtained $(\mathrm{r}=0.94)$ based on following straight line: $\mathrm{t}=3.015+0.89$ (d); $\mathrm{F}=909.4 ;$ d.f. $=1 / 100 ; \mathrm{p}<0.0001$.

TABLE I

Averages of larvae per gramme of Trichinella spiralis detected by trichinoscopy on different muscles

\begin{tabular}{lccccc}
\hline Muscle & $\mathrm{x}$ & $\mathrm{s}$ & $\mathrm{n}$ & $\mathrm{E}$ & $\mathrm{g}$ \\
\hline Triceps brachialis & 1254.8 & 175.9 & 17 & 21332.2 & $\mathrm{a}$ \\
Cuadriceps femoralis & 1298.2 & 181.5 & 17 & 22069.5 & $\mathrm{a}$ \\
Intercostals & 1325.5 & 116.5 & 17 & 22532.8 & $\mathrm{a}$ \\
Masseters & 3993.2 & 284.6 & 17 & 67884.6 & $\mathrm{~b}$ \\
Tongue & 4649.3 & 623.3 & 17 & 79038.3 & $\mathrm{~b}$ \\
Diaphragm & 5662.0 & 747.7 & 17 & 96253.3 & $\mathrm{c}$ \\
\hline Total & & 102 & 309110.7 & \\
\hline
\end{tabular}

Fisher $=21.2 ; \mathrm{p}<0.0001$

$\mathrm{x}$ : average of larvae per gramme; s: standard error; n: number of rats; E: sum of averages; g: group

TABLE II

Averages of larvae per gramme of Trichinella spiralis detected by artificial digestion on different muscles

\begin{tabular}{|c|c|c|c|c|c|}
\hline Muscle & $\mathrm{x}$ & $\mathrm{s}$ & $\mathrm{n}$ & $\mathrm{E}$ & $\mathrm{g}$ \\
\hline Triceps brachialis & 1413.3 & 216.8 & 17 & 24025.6 & $\mathrm{a}$ \\
\hline Intercostals & 1416.2 & 153.1 & 17 & 24076.0 & a \\
\hline Cuadriceps femoralis & 1455.8 & 227.2 & 17 & 24748.3 & $\mathrm{a}$ \\
\hline Masseters & 4951.3 & 443.1 & 17 & 84172.5 & $b$ \\
\hline Tongue & 5081.8 & 725.4 & 17 & 86390.3 & b \\
\hline Diaphragm & 5642.2 & 756.6 & 17 & 95917.6 & $\mathrm{c}$ \\
\hline Total & & & 102 & 339330.3 & \\
\hline
\end{tabular}

Fisher $=18.54 ; \mathrm{p}<0.0001$

$\mathrm{x}$ : average of larvae per gramme; s: standard error; n: number of rats; E: sum of averages; g: group

TABLE III

Compared analysis of averages of larvae per gramme of Trichinella spiralis detected by both methods: trichinoscopy and artificial digestion

\begin{tabular}{lccccc}
\hline Muscle & $\mathrm{x}$ & $\mathrm{s}$ & $\mathrm{n}$ & $\mathrm{E}$ & $\mathrm{g}$ \\
\hline Triceps brachialis & 1334.1 & 138.2 & 34 & 45357.7 & $\mathrm{a}$ \\
Intercostals & 1370.9 & 95.0 & 34 & 46608.9 & $\mathrm{a}$ \\
Cuadriceps femoralis & 1377.0 & 143.8 & 34 & 46817.7 & $\mathrm{a}$ \\
Masseters & 4472.3 & 272.4 & 34 & 152057.2 & $\mathrm{~b}$ \\
Tongue & 4865.6 & 472.4 & 34 & 165428.7 & $\mathrm{~b}$ \\
Diaphragm & 5652.1 & 523.7 & 34 & 192170.7 & $\mathrm{c}$ \\
\hline Total & & 204 & 648440.9 & \\
\hline
\end{tabular}

Fisher=39.1; $\mathrm{p}<0.0001$

$\mathrm{x}$ : averages of larvae per gramme; s: standard error; n: number of rats; E: sum of averages; g: group 


\section{DISCUSSION}

The use of direct methods for the diagnosis of trichinellosis in swine is nowadays recommended in European slaughterhouses, in countries where human cases are registered.

Soulé and Dupouy Camet (1991) considered that the trichinoscopy is less sensitive than artificial digestion. Van Knappen (1980) established that from pigs infected with 500 to 1500 larvae doses, only between $10 \%$ and $20 \%$ showed positive by trichinoscopy compared with $50 \%$ by artificial digestion. Acha and Szyfres (1989) assumed that the artificial digestion method has high sensitivity due to the size of samples that usually are 50 to 100 times heavier than those processed by trichinoscopy. Ruitenberg and Kampelmacher (1970) considered that artificial digestion is at least three times more sensitive than trichinoscopy.

Our study shows that in the experimental model used (rat/rat) and with an inocula of $500 \mathrm{~T}$. spiralis larvae, both methods have similar sensitivity. The distribution of larvae in the chosen muscles maintained an "uniform pattern" in all infected rats; decreasing averages of larvae per gramme from the diaphragm to the triceps brachialis were registered. The diaphragm, tongue and masseters sheltered a significantly higher number of larvae per gramme (Table III). These data coincided with the observations of Gundlach et al. (1994) in rats infected with 500 larvae.

According to our results, we consider that the use of trichinoscopy should not be given up. We think that the differences attributed to the sensitivity of trichinoscopy in respect to artificial digestion is probably associated to mistakes in the application of the technique. It would be advisable to use samples of not less than $1 \mathrm{~g} /$ muscle, and divide them into subsamples of the size indicated in Materials and Methods, in order to achieve a maximum finding of cysts and/or larvae.

As regards the chosen muscles, in the proposed model (rat/rat), the diaphragm, tongue and masseters are best for diagnosis.

The studies to be carried out on pigs, will allow us to indicate with greater accuracy, the chosen muscles in this host with this $T$. spiralis strain.

\section{REFERENCES}

Acha PN, Szyfres B 1989. Zoonosis y enfermedades transmisibles comunes al hombre y a los animales. Publicación Científica No. 503 OPS, 989 pp.

Brusolini CE, Gore FL 1992. Triquinosis: estudio de un brote epidémico en San Martín de los Andes (Neuquén). Vet Arg 9: 89-93.

Gundlach JL, Sadzikowski AB, Tomczuk K, Grzeda M 1994. Distribution of the Trichinella spiralis larvae in the muscles of experimentally infected pigs and rats. Medycyna Weterynarygna 50: 617-619.

Kirby KN 1993. Advanced Data Analysis with Systat. Ed. Van Nostrand Reinhold, New York, 475 pp.

Köhler G, Pfeiffer G 1983. Zur Möglichkeitweiter verkürzung des direkten Trichinellennachweises beim schlachtschwein. Fleischwirtschaft 63: 330333.

Larrieu E 1981. Evolución de la triquinosis en la provincia de Río Negro. Gac Vet (Buenos Aires) 43: $782-787$.

Lison L 1976. Estadística Aplicada a la Biología Experimental. Ed. Universitaria, Buenos Aires, 357 pp.

Nader AJ, Sommerfeld I, Franco A 1986. La triquinosis humana y porcina en la República Argentina. Therios 7: 214-230.

Ruitenberg EJ, Kampelmacher EH 1970. Diagnostische Methoden zur feststellung der invasion mit Trichinella spiralis. Fleischwirtschaft 50: 42-44.

Sokal RR, Rohlf FJ 1984. Introducción a la Bioestadística. Ed. Reverté, Barcelona, 362 pp.

Soulé C, Dupouy Camet J 1991. La Trichinellose: une zoonose en évolution. OIE, Paris, 292 pp.

Van Knappen F, Franchimont JH, Ruitenberg EJ, Baldelli B, Bradley J, Gibson TE, Gottal C, Henriksen SA, Köhler G, Skovgaard N, Soulé C, Taylor SM 1980. Comparison of the enzyme linked immunosorbent assay (ELISA) with three other methods for the detection of Trichinella spiralis infections in pigs. Vet Parasitol 7: 109-121. 